Www.jmscr.igmpublication.org

Impact Factor (SJIF): 6.379

Index Copernicus Value: 79.54

ISSN (e)-2347-176x ISSN (p) 2455-0450

crossrefDOI: https://dx.doi.org/10.18535/jmscr/v6i10.204

Journal Of Medical Science And Clinical Research

\title{
To Study the Prevalence of Diabetic Retinopathy in Diabetics (Type 1 and Type 2) Attending Ophthalmology Outpatient Department in Government Medical College Jammu
}

\author{
Authors \\ Dr Ashwani Kumar ${ }^{1}$, Dr Sakshi Sahni ${ }^{2}$, Dr Neha Devrani ${ }^{3}$ \\ Dept of Ophthalmology, GMC Jammu, India
}

\begin{abstract}
Introduction: Diabetes Mellitus, a disorder of carbohydrate metabolism characterised primarily by hyperglycemia and glycosuria with secondary anomalies of the metabolism of proteins and fats, is a disease the etiology of which is still not clear. Diabetes Mellitus is a common metabolic disorder secondary to lack, diminished efficacy or both of endogenous insulin. Diabetes may be insulin dependent (Type 1 IDDM) or non insulin dependent (Type 2 NIDDM) diabetes mellitus. It is one of the most common non communicable diseases with an increasing incidence worldwide. Among the various manifestations of Diabetes mellitus, diabetic retinopathy is the most common chronic complication associated with it and is the most common cause of legal blindness between the ages of 20 and 65 years. Diabetic Retinopathy is a microangiopathy primarily effecting pre cappilary venules, although larger vessels may also be involved. Bresnick (1967), stated that the prevalence of retinopathy in the diabetic population is positively associated with the duration of diabetes. He also stated that the risk of developing blindness from retinopathy also increases with increase in duration of diabetes. Signs of retinopathy occur in nearly all patients with type1 DM and in 80\% with type 2 DM after 20 years of diabetes mellitus (same duration). Other than being the major cause of legal blindness, diabetes mellitus is leading to loss of productivity and quality of life of patients with diabetes retinopathy with additional socio economic burden on society. However appropriate treatment can lead to decrease in the loss of vision caused by proliferative diabetic retinopathy by $90 \%$.
\end{abstract}

Aims and Objectives

- To assess the prevalence of Diabetic Retinopathy in diabetic patients attending Ophthalmology Outpatient Department at Government Medical College Hospital Jammu.

- To find out the prevalence of patients with NPDR, PDR, Diabetic maculopathy in both Type 1 and Type 2 DM.

Material and Methods: The study was conducted on 150 patients and diagnosed cases of Diabetes mellitus(as per the WHO criteria) attending Eye OPD for ocular examination at the Upgraded Department of Ophthalmology, Government Medical College, Jammu were selected at random and enrolled in the study. The cases were non selective with regards to age, sex, ethnic origin and occupation and type of diabetes. Patients with angle closure glaucoma, hazy media, gestational DM and on long term steroids are excluded from the study. A detailed history of each patient was obtained regarding age, year of diagnosis of diabetes, age at onset and duration of diabetes, family history of diabetes and complete family history .Pupils of both eyes were dilated with $1 \%$ tropicamide eye drops to achieve maximum dilatation. Fundus 
examination of both eyes was done using direct ophthalmoscopy, posterior pole of the retina and macula examination will be done with slit lamp biomicroscopy with 90D lens as well as the periphery was be visualised, indirect ophthalmoscopy with 20D was also be done. Any changes attributable to diabetes were documented Fundus photography and Fluorescein angiography was done in patients where required.

Results: Out of 150 diagnosed cases of diabetes mellitus, 108 patients had retinopathy, thus prevalence was $72 \%$, where as 42 diabetics had no retinopathy(28\%).

Conclusion: It was concluded that diabetic retinopathy in diabetic patients is dependent on certain risk factors and these are age, sex, duration of diabetes, fasting blood sugar levels, altered renal function tests and also type of diabetes.

Keywords: diabetes mellitus (DM), glycosylated haemoglobin(Hb1Ac), non contact tonometer (NCT).

\section{Introduction}

Diabetes Mellitus,a disorder of carbohydrate metabolism characterised primarily by hyperglycemia and glycosuria with secondary anomalies of the metabolism of proteins and fats, is a disease the etiology of which is still not clear. Diabetes Mellitus is a common metabolic disorder secondary to lack, diminished efficacy or both of endogenous insulin. Diabetes may be insulin dependent (Type 1 IDDM) or non insulin dependent (Type 2 NIDDM) diabetes mellitus. It is one of the most common non communicable diseases with an increasing incidence worldwide. Among the various manifestations of Diabetes mellitus, diabetic retinopathy is the most common chronic complication associated with it and is the most common cause of legal blindness between the ages of 20 and 65 years. Diabetic Retinopathy is a microangiopathy primarily effecting precappilary venules, although larger vessels may also be involved. Bresnick (1967), stated that the prevalence of retinopathy in the diabetic population is positively associated with the duration of diabetes. He also stated that the risk of developing blindness from retinopathy also increases with increase in duration of diabetes. Signs of retinopathy occur in nearly all patients with type1 DM and in $80 \%$ with type $2 \mathrm{DM}$ after 20 years of diabetes mellitus(same duration). Other than being the major cause of legal blindness ,diabetes mellitus is leading to loss of productivity and quality of life of patients with diabetes retinopathy with additional socio economic burden on society. However appropriate treatment can lead to decrease in the loss of vision caused by proliferative diabetic retinopathy by $90 \%$.

\section{Material and Methods}

The proposed study was conducted on 150 diagnosed cases of Diabetes mellitus (as per WHO criteria) attending Eye OPD for ocular examination at the upgraded department of Ophthalmology, Govt. Medical college Jammu. The cases were selected at random and enrolled in the study. Patients with non dilating pupil, angle closure glaucoma, hazy media, gestational DM and patients on long term use of systemic steroids were excluded from the study. A detailed history was obtained including duration of diabetes, family history, history of smoking and alcohol intake, associated hypertension or any other illness. Complete ocular examination was done including visual acuity, intraocular pressure, slit lamp examination and gonioscopy were done.

Pupils of both eyes were dilated with $1 \%$ tropicamide eye drops and fundus examinmton of both eyes was done using direct ophthalmoscopy and posterior pole and macular examination was done with slit lamp examination with 90D lens. Indirect ophthalmoscopy was done using $20 \mathrm{D}$ lens. Any changes attributable to diabetes were documented. The presence or absence of maculopathy was documented and fundus findings were graded as:

1. No signs of retinopathy

2. Non proliferative diabetic retinopathy (NDPR)

3. Proliferative diabetic retinopathy(PDR)

4. Diabetic Maculopathy

5. Diabetic retinopathy with maculopathy

Blood samples after an overnight fasting were drawn for blood sugar fasting and for total lipid 
profile estimation. Fundus photography was done in patients where required.

\section{Statistical Analysis}

The analysis was performed using statistical software study population3 version of windows and thus the point prevalence was calculated. Relationship of diabetic retinopathy was assessed using univariate analysis. Logistic regression analysis was used to assess the independent effect of each variable on theotcome of diabetic retinopathy. A $p$ value of $<0.05$ was considered as statistically significant.

\section{Aims and Objectives}

- To assess the prevalance of Diabetic Retinopathy in diabetic patients attending Ophthalmology Outpatient Department at Government Medical College Hospital Jammu.

- To find out the prevalance of patients with NPDR, PDR, Diabetic maculopathy in both Type 1 and Type $2 \mathrm{DM}$.

\section{Results}

Following are the observations of our study:

Table 1: Distribution of diabetic patients (with or without retinopathy) according to duration of diabetes in years

\begin{tabular}{|l|c|c|}
\hline \multirow{2}{*}{ Duration (Yrs.) } & \multicolumn{2}{|c|}{ Diabetic Retinopathy } \\
\cline { 2 - 3 } & Absent & Present \\
\cline { 2 - 3 } & No.(\%) & No.(\%) \\
\hline $0-5$ & $42(100)$ & - \\
\hline $6-11$ & - & $22(20)$ \\
\hline $12-21$ & - & $73(68)$ \\
\hline$>21$ & - & $13(12)$ \\
\hline Total & $42(100)$ & $108(100)$ \\
\hline
\end{tabular}

Out of 42 patients without retinopathy all had diabetes of a duration of less than 5 years. With chi-square test, p-value came to be 0.000 (highly significant), thus chances of retinopathy increase with the increase in duration of diabetic retinopathy.

Table 2: Distribution of diabetic patients (with or without retinopathy) according to type of diabetes (type I or Type II)

\begin{tabular}{|l|c|c|c|c|}
\hline Type of Diabetes & \multicolumn{2}{|c|}{ Diabetic retinopathy } & Crude odd's ratio & 95\% confidence interval \\
\hline & Absent & Present & & \\
\hline & No.(\%) & No.(\%) & & \\
\hline Type I & - & $11(10)$ & \multicolumn{2}{|c|}{ Undefined } \\
\hline Type II & $42(100)$ & $97(90)$ & & \\
\hline Total & $42(100)$ & $108(100)$ & - & - \\
\hline
\end{tabular}

Out of 108 DR patients, 97 had type 2 diabetes 0.03 (statistically significant), thus patients with (90\%) whereas only 11 had type 1 diabetes(10\%). With Fisher exact test $\mathrm{p}$ value came to be type 1 diabetes have more chances of developing retinopathy.

Table 3: Distribution of diabetic patients (with or without retinopathy) according to levels of blood glucose (fasting)

\begin{tabular}{|l|c|c|c|c|}
\hline $\begin{array}{l}\text { Blood Glucose } \\
\text { Levels(fasting) }\end{array}$ & \multicolumn{2}{|c|}{ Diabetic retinopathy } & $\begin{array}{c}\text { Crude odd's } \\
\text { ratio }\end{array}$ & $\begin{array}{c}\text { 95\% confidence } \\
\text { interval }\end{array}$ \\
\hline & Absent & Present & & \\
\hline & No.(\%) & No.(\%) & & - \\
\hline$<126$ & $35(86)$ & $29(27)$ & $1.00(\mathrm{ref})$ & $5.07-38.09$ \\
\hline$>126$ & $7(14)$ & $79(73)$ & 13.62 & - \\
\hline Total & $42(100)$ & $108(100)$ & - & - \\
\hline
\end{tabular}

Out of 42 diabetic patients without retinopathy, 35 patients had blood glucose (fasting) levels more than $126 \mathrm{mg} \%$ (86\%), and only 7 had levels more than $126 \mathrm{mg} \%$ (14\%). With chi square test p-value came to be 0.0001 (highly statistically significant ) thus patients with blood glucose (fasting) more than $126 \mathrm{mg} \%$ have more chances of developing retinopathy. 
Table 4: Distribution of diabetic patients (with or without retinopathy) according to levels of associated Hypertension

\begin{tabular}{|l|c|c|c|c|}
\hline $\begin{array}{l}\text { Associated } \\
\text { Hypertension }\end{array}$ & \multicolumn{2}{|c|}{ Diabetic retinopathy } & Crude odd's ratio & 95\% confidence interval \\
\hline & Absent & Present & & \\
\hline & No.(\%) & No.(\%) & & - \\
\hline Absent & $31(81)$ & $73(68)$ & $1.00(\mathrm{ref})$ & $0.57-3.25$ \\
\hline Present & $11(29)$ & $35(32)$ & 1.35 & - \\
\hline Total & $42(100)$ & $108(100)$ & - & \\
\hline
\end{tabular}

Out of 42 diabetic patients without retinopathy, 11 patients had associated hypertension (29\%) whereas 31 patients had no associated hypertension $(81 \%)$.
With chi square test p-value came to be 0.45 (statistically not significant).

Table 5: Distribution of diabetic patients (with or without retinopathy) according to presence of altered lipid profile

\begin{tabular}{|l|c|c|c|c|}
\hline $\begin{array}{l}\text { Altered Lipid } \\
\text { Profile }\end{array}$ & \multicolumn{2}{|c|}{ Diabetic retinopathy } & $\begin{array}{c}\text { Crude odd's } \\
\text { ratio }\end{array}$ & $\begin{array}{c}\text { 95\% confidence } \\
\text { interval }\end{array}$ \\
\hline & Absent & Present & & \\
\hline & No.(\%) & No.(\%) & & - \\
\hline Unaltered & $35(86)$ & $79(73)$ & $1.00(\mathrm{ref})$ & - \\
\hline Altered & $7(14)$ & $29(27)$ & 1.84 & $0.68-5.11$ \\
\hline Total & $42(100)$ & $108(100)$ & - & - \\
\hline
\end{tabular}

Out of 42 diabetic patients without retinopathy, 7 patients had altered lipid profile (14\%) whereas 35 patients had unaltered lipid profile $(86 \%)$.
With chi-square test $\mathrm{p}$ value came to be 0.18 (statistically significant).

Table 6: Distribution of NPDR (Non proliferative diabetic retinopathy), PDR (proliferative diabetic retinopathy) and Maculopathy among diabetic retinopathy patients according to duration of diabetes

\begin{tabular}{|l|c|c|c|}
\hline Duration of diabetes (in Yrs) & \multicolumn{3}{|c|}{ Diabetic retinopathy } \\
\hline & NPDR & PDR & MACULOPATHY \\
\hline 0 to 5 & No.(\%) & No.(\%) & \\
\hline 6 to 11 & - & - & - \\
\hline 12 to 21 & $20(22)$ & - & $2(18 \%)$ \\
\hline$>21$ & $67(75)$ & $4(50)$ & $2(18 \%)$ \\
\hline Total & $2(2)$ & $4(50)$ & $7(64 \%)$ \\
\hline
\end{tabular}

Out of 108 diabetic retinopathy patients $82.5 \%$ (89/108) had NPDR,7.5\% (8/108) had PDR and $10 \%(11 / 108)$ had maculopathy.

\section{Discussion}

In our study, out of 150 diabetics who attended eye OPD, 108 had some retinopathy, thus overall prevalence was $72 \%$. Out of 108 patients with diabetic retinopathy, 89 patients had NPDR (59.3\%), 8 patients had PDR (5.4\%) and 11 patients had maculopathy(7.3\%).
Qogonokana et al (2010) did a hospital based study on 50 diabetes mellitus patients attending eye OPD and found the prevalence of diabetic retinopathy to be $86 \%$ with $76 \%$ NPDR and $10 \%$ PDR.

Jain et al 1988 found the prevalence of diabetic retinopathy was $42.9 \%$ in his study on diabetic subjects.

Raman et al 2009 found that the prevalence of diabetic retinopathy in diabetics in a study based population based study was $18 \%$. 
Dandona et al 1999 found that the prevalence of diabetic retinopathy in a screened population in south India was $1.78 \%$

Guerci et al 1999 did his study on 341 type 1 DM patients and found that 123 had no retinopathy, 188 had mild to moderate NPDR(55.1\%)and 30 had PDR $(8.7 \%)$.

The higher prevalence of diabetic retinopathy in our study could be due to the fact that ours is a hospital based study in which diabetics attending eye OPD for their ophthalmological check up were taken into consideration.

In our study on 150 patients with diabetes, out of which 108 had retinopathy, it was found that no patient with duration of diabetes less than 5 years had retinopathy, 73 patients $67 \%$ of those with retinopathy) were with duration of diabetes between 12-21 years, 13 patients (12\%) of those with retinopathy) had a duration of more than 21 years. It was also found that 37 patients $35 \%$ of those withretinopathy0were in the age group of 51-60 years followed by 36 patients $(33 \%)$ in the age group of 41-50 years.

Kahn et al 1975 found a strong association between diabetic retinopathy and duration of diabetes mellitus.

Kim et al1998 in their study on type 2 DM found that mean duration of diabetes in subjects with DR was $11.0 \pm 0.3 \%$ years as compared to $5.6 \pm 0.3 \%$ years in diabetics without diabetic retinopathy, difference being statistically significant $(\mathrm{p}<0.05 \%)$.

Zander et al2000 found that irrespective of the type of diabetes ,diabetic patients with long standing diabetes mellitus have an increased risk of developing retinopathy.

Agarwal et al 2001 found a strong association between prevalence of DR and duration of DM, BMI, glycemic control, and dyslipidemia in type 1 DM patients.

The results in our study were similar to that of other authors, thus according to our study chances of retinopathy are more with increased duration of diabetes. $p=0.00$. (highly statistically significant).
In our study on diabetic retinopathy, out of 108 patients with retinopathy, $73 \%$ had blood glucose fasting levels more than $126 \mathrm{mg} \%$ and $27 \%$ had levels less than $126 \mathrm{mg} \%$.

Van Leiden et al (2002) in their study found that $7 \%$ of patients with retinopathy had normal glucose metabolism, $11 \%$ of patients had impaired glucose metabolism and $34 \%$ of patients with retinopathy were known cases of diabetes mellitus.

Thus our study is similar to that of other authors and according to our study patients with higher blood glucose (fasting) have more chances of developing retinopathy, $\mathrm{p}<0.0001$ (statistically significant).

In our study, out of 108 diabetic retinopathy patients, 29\% had associated hypertension and $71 \%$ had no hypertension.

Ballantyne et al (1943) found that hypertension was associated in 50\% of diabetes with retinopathy.

Bajpai et al (1979) found that hypertension was associated with retinopathy in $31.4 \%$ of patients.

Our study is not similar to that of other studies and it shows no significant association between the hypertension and diabetes.

\section{Conclusion}

It was concluded that diabetic retinopathy in diabetic patients is dependent on certain risk factors and these are age, sex, duration of diabetes, fasting blood sugar levels, altered renal function tests and also type of diabetes.

\section{References}

1. Bresnick GH. Diabetic retinopathy. In: Peyman GA, Sanders DR, Goldberg MF(edtrs). Principals and practice of ophthalmology. Ist edition. Jaypee Brothers, New Delhi 1987.pp.1205-73.

2. Qogonokana MQ, Bian G, RamkeJ, Garcia J,Szettu J. Diabetic retinopathy in a hospital eye clinic in Soloman islands. Clin Experiment Ophtrhalmol 2010;38: 862-66. 
3. Jain IS. Vision threatening diabetic retinopathy. Ind J ophthalmol 1988;36 1-3.

4. Raman R, Rani PK, Reddi RS. Prevalence of diabetic retinopathy in urban India.2009;116(2):311-18.

5. Dandona L, Dandona R, Nadiwilath TJ,et al. Population based assessment of diabetic retinopathy in an urban population in South India.Br J Ophthalmol 1999;83:93740.

6. Guerci B ,Meyer L,Sommer S, et al. Severity of diabetic retinopathy is linked to lip[oprotein (a) in type 1 diabetes patients. Diabetes Metab 1999;25(5):412-18.

7. Kahn HA and Bradley RF. Prevalence of diabetic retinopathy. $\mathrm{Br} \mathrm{J}$ Ophthalmol 1975;59:345-49.

8. Kim CH, Hong SK, Park HJ, Yoon YH,Park JY,Lee UK. High serum lipoprotein(a) levels in Korean type 2 diabetes patients with proliferative diabetic retinopathy.Diabetes Care 1998;21;214951.

9. Zander E, Herfurth S, Bohl B,et al. Maculopathy in patients with diabetes mellitus type 1 and type 2: associated with risk factors. $\mathrm{Br}$ J Ophthalmol 2000; 84:871-76.

10. Agarwal RP, Singhla M, Vyas SP , Hussain S, Jain GS, Kochar DR. Prevalence of retinopathy and its relation with various risk factors in type 1 Diabetes Mellitus-Hospital based study. Int J Diab Dev Ctries 2001;21(4);184-90.

11. Van Leiden, HA, Heine RJ, Dekker JM, et al. Diabetic retinopathy associated with mortality and cardiovascular diseases. The EURODIAB prospective compilation study. Diabetes Care 2005;28:1383-89.

12. Bajpai HS, Mehra KS ,Singh VP, Tikko SK, Aggarwal JK and Sharma A. Diabetic retinopathy : A clinic-biochemical study . Int J Ophthalmol 1979;27:12-15. 